\title{
Management of upper calyceal stone by percutaneous nephrolithotomy through lower calyx access: prone versus supine position
}

\author{
Tarek Soliman, Mostafa Khalil", Rabea Omar, Ahmed Mohey, Shabieb Ahmed, Hammoda Sherif \\ and Mohamed Abdelazim
}

\begin{abstract}
Background: The best way in the management of calyceal stone by percutaneous nephrolithotomy (PCNL) is to go directly into the desired calyx. However, in upper calyx, this direct entry may be associated with undesired complications, and through lower calyx is limited in prone PCNL. Recently, there is another option about reaching it through the lower calyx in supine position with more accessibility and better manipulation. This study aimed to evaluate the management of the upper calyceal stone by PCNL through lower calyx access in prone versus supine position.
\end{abstract}

Methods: A total of 38 patients with upper calyceal stone $(\geq 2 \mathrm{~cm})$ were randomly divided into two groups; the first group included 18 patients managed by PCNL in the prone position, and the second group included 20 patients managed in supine position. All data of both procedures were collected and statistically analyzed to compare between both groups.

Results: There is no statistically significant difference between groups as regards demographic and stone characters. The angle between the access to the lower calyx and access of the upper calyx was significantly wider in the supine group versus prone group $\left(130.2^{\circ} \pm 23.46^{\circ} \mathrm{vs} .89 .67^{\circ} \pm 14.56^{\circ}\right.$, respectively). The mean operative and fluoroscopy time was significantly longer in the prone group. There is no significant difference in intraoperative or postoperative morbidity. The stone-free rate was significantly higher in the supine group than the prone group ( $85 \%$ vs $38.9 \%$, respectively). Also stone approachability was higher in the supine group than prone group ( $95 \%$ vs. $66.7 \%$, respectively).

Conclusion: Management of upper calyceal stone by PCNL through the lower calyx is safe, but it is more effective in the supine position than in prone position.

Keyword: Percutaneous nephrolithotomy, Renal stone, Upper calyx, Prone, Sopine

\section{Background}

The American urological association/endourological society guideline on the surgical management of stones stated that there are many options of treatment for symptomatic non-obstructing calyceal stone [1].

*Correspondence: mostafa.mahmod@gmail.com

Department of Urology, Faculty of Medicine, Benha University, Benha, Egypt
The upper calyceal stone represents about $15 \%$ of calyceal stones [2], shock wave lithotripsy (SWL) is considered the first line of treatment of such stones when their size is less than $2 \mathrm{~cm}$, and percutaneous nephrolithotomy (PCNL) is indicated when their size is $2 \mathrm{~cm}$ or more or after failure of SWL [3].

The best way in the management of calyceal stone by PCNL is to go directly into the desired calyx; however, in upper calyx, this direct entry may be associated with undesired complication like plural or lung injury, 
hydrothorax, pneumothorax, and through lower calyx is limited in prone PCNL [4]. However, recently there is another option about reaching it through the lower calyx in supine position with more accessibility and better manipulation because there is some anatomical difference between the supine and prone positions while doing this approach $[5,6]$. In the current study, we compared between supine and prone PCNL in the management of upper calyceal stone through lower calyx access.

\section{Methods}

\subsection{Study design}

Between February 2014 and January 2018, a total of 38 patients with upper calyceal stones were included in the study. All patients were presented to the outpatient clinic of our university hospital with stone(s) in the upper calyx. The inclusion criteria of the study were a stone size of $2 \mathrm{~cm}$ or more and/or failed SWL. Patients with congenital anomalies of the urinary tract, morbid obesity, and uncorrected coagulopathy were excluded from the study. The patients were randomized into two groups by simple randomization using a closed envelopes method; the first group included 18 patients who were managed by PCNL through lower calyx in the prone position, and the second group included 20 patients managed by the same approach but in the supine position. All patients were evaluated by detailed clinical history, serum creatinine and blood urea nitrogen, bleeding and coagulation profile, urine culture and sensitivity and radiological investigations in the form of plain X-ray urinary tract, ultrasound abdomen and pelvis, and non-contrast computed tomography (NCCT) of urinary tract. In the prone group, NCCT was done in a prone position, and in the second group, it was made while patients in the supine position. All patients with urinary tract infections were treated before surgery. The study was approved by the local health committee, and written informed consent was signed by all patients.

\subsection{Surgical technique}

All procedures were done under general anesthesia, and firstly, the patient was put in lithotomy position for insertion of six French ureteric catheter; then, in the group of prone PCNL, the patient was turned prone with putting a bridge or towel under his chest and pelvis leaving the abdomen free for respiration and puncture of the lower calyx was performed, and then, dilatation of the tract was made either by Amplatz Teflon dilator or Alken telescopic metal dilators, till 28 French Amplatz sheath was inserted and rigid nephroscopy was used to approach the pelvicalyceal system and after visualization of the stone. The disintegration of the stone was performed by pneumatic lithoclast, and after that fragment was removed.
In the second group, the patient was in the supine position with the side of interest being adjusted to be at the edge of the table, and then, the same procedure was applied. At the end of the procedure, visualization of the pelvicalyceal system by nephroscopy and fluoroscopy was performed to see if there is any residual stone. Finally, antegrade pyelography was done to exclude any perforation or extravasation, and a 20 French nephrostomy tube was fixed.

Pelvi-abdominal ultrasound and plain X-ray urinary tract (PUT) were done after $24 \mathrm{~h}$; if there is a significant residual larger than $4 \mathrm{~mm}$, a second-look PCNL was carried out if the stone was accessible or SWL if not. After a 3-month evaluation, the final stone-free status was performed by PUT, pelvi-abdominal ultrasound, or low-dose NCCT if indicated.

\subsection{Statistical analysis}

Preoperative patients and stone data, including the CT data of the patients, especially the angle between the upper calyx and the axis to the lower calyx, operative data, operative time (calculated from cystoscopy till fixation of nephrostomy tube), postoperative morbidity, and stone-free rate, were collected. These data were tabulated and analyzed using the computer program Statistical Package for Social Science (SPSS) version 20. Descriptive statistics were calculated in the form of mean and standard deviation for quantitative data and frequency and distribution for qualitative data. In the statistical comparison between the different groups, the significance of difference was tested using one of the following tests: $t$ test to compare mean of two groups of quantitative data, and inter-group comparison of categorical data was performed by Chi-square test $\left(\chi^{2}\right.$-value $)$ and Fisher's exact test (FET).

\section{Results}

The study included 38 patients randomly divided into two groups, the first group included 18 patients who underwent prone PCNL, and the second group included 20 patients who were managed by supine PCNL. The mean age of patients in the prone group was $46.44 \pm 13.6$ years, where $66.7 \%$ were male and $33.3 \%$ were female, and in the supine group, the mean age was $47.1 \pm 14.3$ years. Of them, $60 \%$ were male and $40 \%$ were female with no statistically significant difference between the two groups. There was also no statistically significant difference between them regarding mean body mass index (BMI), preoperative urinary tract infection (UTI), and recurrence (Table 1).

The mean stone size in prone group was $20.3 \pm 2.07 \mathrm{~mm}$ and in the second group was $20.3 \pm 1.7 \mathrm{~mm}$ without significant difference, and also there is no statistically 
Table 1 Patients' demographics

\begin{tabular}{|c|c|c|c|}
\hline & $\begin{array}{l}\text { Prone PCNL } \\
N=18\end{array}$ & $\begin{array}{l}\text { Supine PCNL } \\
N=20\end{array}$ & $P$ value \\
\hline Age (years), mean \pm SD & $46.44 \pm 13.6$ & $47.1 \pm 14.3$ & 0.89 \\
\hline \multicolumn{4}{|l|}{ Sex } \\
\hline Male & $12(66.7)$ & $12(60.0)$ & 0.67 \\
\hline Female & $6(33.3)$ & $8(40.0)$ & \\
\hline $\mathrm{BMI}(\mathrm{kg})$, mean $\pm \mathrm{SD}$ & $29.78 \pm 2.05$ & $33.05 \pm 8.88$ & 0.14 \\
\hline Recurrent & $2(11.1)$ & $5(25.0)$ & 0.41 \\
\hline Preoperative UTI & $3(16.7)$ & $3(15.0)$ & 1.0 \\
\hline
\end{tabular}

Unless otherwise indicated, data represent the number with percentage in parenthesis

$N$ number, SD standard deviation, UTI urinary tract infection, $B M I$ body mass index

Table 2 Stone and CT characters

\begin{tabular}{|c|c|c|c|}
\hline & $\begin{array}{l}\text { Prone PCNL } \\
N=18\end{array}$ & $\begin{array}{l}\text { Supine PCNL } \\
N=20\end{array}$ & $P$ value \\
\hline \multicolumn{4}{|l|}{ Stone side, no (\%) } \\
\hline Right & $11(61.1)$ & $10(50.0)$ & 0.49 \\
\hline Left & $7(38.9)$ & $10(50.0)$ & \\
\hline Stone size $(\mathrm{mm})$ & $20.3 \pm 2.07$ & $20.3 \pm 1.7$ & 0.9 \\
\hline Skin-to-stone distance (mm) & $94.0 \pm 16.22$ & $91.7 \pm 25.23$ & 0.74 \\
\hline Body wall thickness (mm) & $62.11 \pm 12.99$ & $59.75 \pm 12.39$ & 0.56 \\
\hline $\begin{array}{l}\text { Angle between upper and } \\
\text { lower calyceal accesses }\end{array}$ & $89.67 \pm 14.56$ & $130.2 \pm 23.46$ & $0.001^{* *}$ \\
\hline
\end{tabular}

Unless otherwise indicated, data represent the mean \pm SD

$N$ number, SD standard deviation

**High significant difference

significant difference between other stone parameters and NCCT measurements, except for the angle between the axis to the lower calyx and that of the upper calyx, as it was significantly wider in supine group than in prone group $\left(130.2^{\circ} \pm 23.46^{\circ}\right.$ vs. $89.67^{\circ} \pm 14.56^{\circ}$, respectively, $P<0.001$ ) (Table 2 ). The mean operative time and fluoroscopy time were significantly longer in the prone group than that in the supine group. Operative time was $113.72 \pm 11.73 \mathrm{~min}$ in the prone group versus $80.95 \pm 10.26 \mathrm{~min}$ in the supine group $(P=0.01)$. In prone group, fluoroscopy time was $276.39 \pm 35.49$ s, while in the supine group was $209.05 \pm 36.95 \mathrm{~s}(P=0.001)$.

There was no statistically significant difference between both groups regarding bleeding necessitating blood transfusion, as there was significant bleeding during the procedure in two patients $(11.1 \%)$ in prone position and only in one patient $(5 \%)$ in supine position and in all of them, this was managed by fixation of nephrostomy tube as a tamponade and was clamped for $60 \mathrm{~min}$, and a second look was performed after $48 \mathrm{~h}$ or more if hematuria was still present. There was a postoperative fever in three patients $(16.7 \%)$ in the prone group and in two patients
Table 3 Operative and postoperative data

\begin{tabular}{llll}
\hline & $\begin{array}{l}\text { Prone PCNL } \\
\mathbf{N = 1 8}\end{array}$ & $\begin{array}{l}\text { Supine PCNL } \\
\mathbf{N = \mathbf { 2 0 }}\end{array}$ & P value \\
\hline $\begin{array}{l}\text { Operative times (min), } \\
\text { mean } \pm \text { SD }\end{array}$ & $113.72 \pm 11.73$ & $80.95 \pm 10.26$ & $0.01^{* *}$ \\
$\begin{array}{l}\text { Fluoroscopic time (s), } \\
\text { mean } \pm \text { SD }\end{array}$ & $276.39 \pm 35.49$ & $209.05 \pm 36.95$ & $0.001^{* *}$ \\
$\begin{array}{l}\text { Blood transfusion } \\
\text { Postoperative fever }\end{array}$ & $2(11.1)$ & $2(5)$ & 0.55 \\
$\begin{array}{l}\text { Upper calyx approachability } \\
\text { Stone-free }\end{array}$ & $12(16.7)$ & $2(10)$ & 0.47 \\
\hline
\end{tabular}

Unless otherwise indicated, data represent the number with percentage in parenthesis

$N$ number, $S D$ standard deviation

**High significant difference

(10\%) in the supine position. The stone-free rate was significantly higher in the supine PCNL group (85\%) than in prone PCNL (38.9\%) $(P=0.03)$ (Table 3).

Upper calyx was approached, and stone could be manipulated in 19 patients in the supine group (95\%) and in $12(66.7 \%)$ patients in the prone group, and this difference was statistically significant (Table 3 ).

In the prone position, upper calyx was approached and stone could be manipulated in 12 patients $(66.7 \%)$ with significant residual stone in seven patients, one of them underwent second-look PCNL and became stone-free, and the other six patients underwent SWL and one of them became stone-free after 3-month follow-up.

In the supine group, the upper calyx was approached in 19 patients (95\%), there were significant residual stones in six patients, three of them underwent secondlook PCNL and became stone-free, and the other three patients underwent SWL and one of them became stonefree after 3-month follow-up. Flow chart of the study is shown in Fig. 1.

\section{Discussion}

More than two decades passed since introduction of supine PCNL, and the approaches are gaining more popularity as it offers many advantages over prone PCNL, being of single patient position throughout surgery, easier patient ventilation and anesthesia, less incidence of organ injury, more comfortable situation for the surgeon (sitting instead of standing), and less time is needed in patient of combination of other endourological procedures like retrograde intrarenal surgery (RIRS) $[7,8]$. Direct access to the upper calyx in management of isolated upper calyceal stone is usually accomplished by supracostal, intercostal, or subcostal approach which is associated with potential risk of pleural and lung injury and hemorrhagic insults, and even familiarity with the 


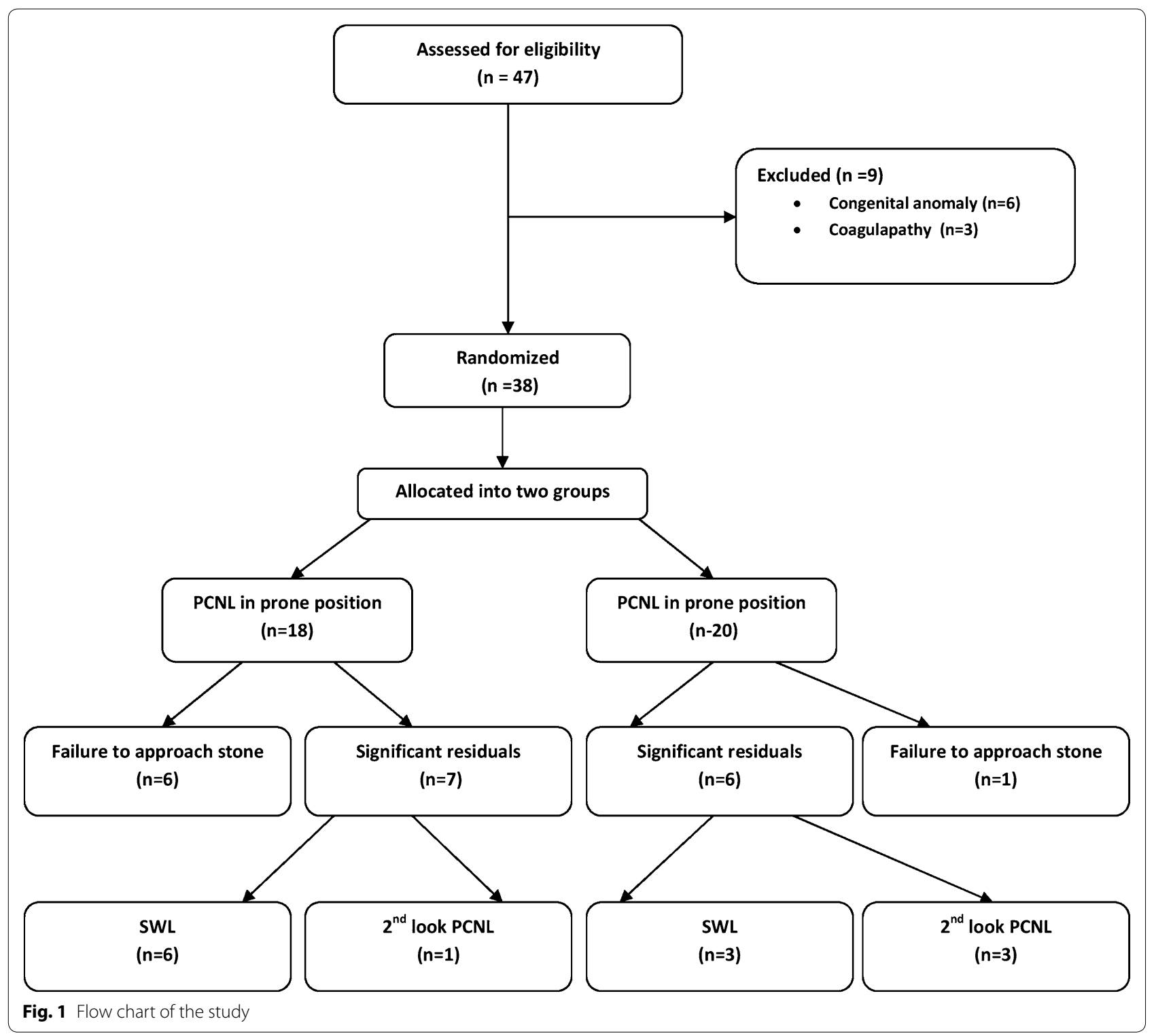

approach and experience can minimize the rate of these complications, but it is still up to $10 \%[9,10]$.

The lower calyceal access in the prone position is of lower morbidity; however, it is of limited accessibility to the whole collecting system and the upper calyx $[5,11]$. In supine position, the puncture is always locating below the posterior axillary line and between the last rib and iliac crest, which means that it is more lateral than the puncture in prone position, with different relationships between the internal anatomy of the calyces and the axis of the tract and nephroscope in that position than in prone position making the angle between the upper calyx and the access to the lower calyx wider in supine position $[5,12]$.
In the current study, PCNL for the upper calyceal stone was carried out through the lower calyx access in 38 patients; after randomization into two groups, the procedure was done in the prone position in 18 patients and in the remaining 20 in the supine position. Both groups showed homogeneity as regards demographic and stone characters as there was no statistically significant difference between them in these data and thus reduce the effect of any of these findings on the outcome of the procedures.

CT considered the cornerstone in preoperative diagnosis and planning of management in renal stones [13], and it was performed for both groups and showed the insignificant difference between them as regards mean 
skin-to-stone distance and mean body wall thickness. The angle between the axis of the lower calyx and the upper calyx was statistically significantly wider in the supine group than in prone group $\left(130.2^{\circ} \pm 23.46^{\circ}\right.$ vs. $89.67^{\circ} \pm 14.56^{\circ}$, respectively). Sofer et al. reported a similar result about this angle in their study that compares the approachability to the upper calyx in supine and prone position ( $141^{\circ}$ vs. $84^{\circ}$, respectively) [5]. The angle between the entered calyx and the desired calyx is one of the most important predictors to approach the desired calyx, a wider angle is correlated with better accessibility to the desired calyx, and the acute angle is correlated with the failed approach to the upper calyx, and the calyx cannot be accessed if this angle is less than $75^{\circ}[6,13]$.

The mean operative time was statistically significantly shorter in supine group $(80.95 \pm 10.26$ vs. $113.72 \pm 11.73$, respectively), many studies showed this difference in operative time due to the added time for patient repositioning in prone position whatever the size or site of the stone and the approach [14, 15], and this difference in time was also noticed in the study of Sofer et al. [5] who did a similar approach to the upper calyx; however, it was statistically insignificant and this might be due to the estimation of the time for approachability only in this study.

The rate of blood transfusion in the current study due to significant bleeding in the supine position was $5 \%$ and $11.1 \%$ in the prone position without significant difference. Generally, the blood transfusion rate during PCNL is ranging from 0 to $20 \%$ with an average of $7 \%[16,17]$. In a meta-analytic study done by Yuan et al. [15], they reported a significantly lower rate of blood transfusion in the supine position than in prone position $(P=0.02)$; however, in another meta-analytic study, there was no statistically significant difference $(P=0.08)[18]$.

In the current study, the rate of postoperative fever was lower in the supine group, but this difference was insignificant. In the supine position, the irrigating pressure is lower with less fluid absorption and a lower rate of postoperative fever. Patel et al. and Yuan et al. found this lower rate is of highly significant difference $(P \leq 0.0001)$ $[14,15]$.

In our study, the stone-free rate was statistically significantly higher in supine group than that of prone group ( $85 \%$ vs. $38.9 \%$, respectively, $P=0.03$ ), and this is most probably due to the more significant approachability of the upper calyx in the supine position and mostly due to significant difference in the angle between the axis of the lower calyx and the upper calyx in the two approaches. In 2010, Liu et al. [19] reported in their meta-analytic study that there was no statistically significant difference between the two positions in stone-free rate; however, in other recent meta-analytic studies the stone-free rate is significantly higher in prone PCNL due to wider range of nephroscope manipulation, easier access to the upper calyx when needed, and more distension of the pelvicalyceal system which provided better vision $[14,15,20]$.

Two recent studies evaluated the same approach through the lower calyx to reach the upper calyx; however, they evaluated the approachability only, and they included multiple and staghorn stones in their study which is not the matter in our study as we were more precise in selection criteria, by including only patients with upper calyceal stone $[5,6]$. Sofer et al. found in their first study that the approachability to the upper calyx was significantly higher in supine group than in prone $(80 \%$ vs. $20 \%$, respectively, $P>0.0001$ ) [5], and in the other study [6] the stone-free rate in supine position the was $88 \%$, and these results were matched to large degree to that of the current study in which stone approachability was $66.7 \%$ in prone group versus $95 \%$ in supine group.

The limitation in the current study is the relatively small number of patients, but it was due to the strict selection criteria of upper calyceal stone.

\section{Conclusion}

PCNL of the upper calyceal stone through lower calyx access is a safe approach in either supine or prone position. However, it is more effective in term of success to reach the stone in the supine position than in prone one, and hence, the stone-free rate is higher in the supine position.

\section{Abbreviations}

BMI: Body mass index; FET: Fisher exact test; NCCT: Non-contrast computed tomography; PCNL: Percutaneous nephrolithotomy; PUT: Plain X-ray urinary tract; RIRS: Retrograde intrarenal surgery; SPSS: Statistical Package for Social Science; SWL: Shock wave lithotripsy; UTI: Urinary tract infection; vs: Versus.

\section{Acknowledgements}

The authors thank all staff members and colleagues in Urology departmentBenha University for their helpful cooperation and all the study participants for their patience and support.

\section{Authors' contributions}

TS and MK were involved in concept, design, supervision, processing, writing a manuscript, and critical analysis. RO was involved in processing, writing a manuscript, and critical analysis. AM was involved in design, processing, writing a manuscript, and critical analysis. SA was involved in writing a manuscript and critical analysis. HS was involved in writing a manuscript and critical analysis. MA was involved in concept, design, supervision, processing, and reviewing the manuscript. All authors read and approved the final manuscript.

\section{Funding}

The authors declare that this work has not received any funding.

\section{Availability of data and materials}

The datasets used and/or analyzed during the current study is available from the corresponding author on reasonable request.

\section{Competing interests}

The authors declare that they have no competing interests. 


\section{Consent for publication}

Not applicable.

\section{Ethics approval and consent to participate}

The study was approved by the Research Ethics Committee at Faculty of Medicine, Benha University (REC-FOMBU), and written informed consent was obtained from all patients. Ethics committee reference number is IDIRB2017122601

Received: 25 December 2019 Accepted: 28 January 2020

Published online: 12 May 2020

\section{References}

1. Assimos D, Krambeck A, Miller NL, Monga M, Murad MH, Nelson CP, Pace KT, Pais VM Jr, Pearle MS, Preminger GM, Razvi H, Shah O, Matlaga BR (2016) Surgical management of stones: American Urological Association/ Endourological Society Guideline, PART II. J Urol 196(4):1161-1169

2. Stening SG, Bourne S (1998) Supracostal percutaneous nephrolithotomy for upper pole caliceal calculi. J Endourol 12(4):359-362

3. Türk C, Petř́k A, Sarica K, Seitz C, Skolarikos A, Straub M, Knoll T (2016) EAU guidelines on interventional treatment for urolithiasis. Eur Urol 69(3):475-482

4. Özgör F, Küçüktopcu O, Şimşek A, Sarılar Ö, Binbay M, Gürbüz G (2015) Percutaneous nephrolithotomy for isolated calyceal stones: how important is the stone location? Turk J Urol 41(4):171-176

5. Sofer M, Giusti G, Proietti S, Mintz I, Kabha M, Matzkin H, Aviram G (2016) Upper calyx approachability through a lower calyx access for prone versus supine percutaneous nephrolithotomy. J Urol 195(2):377-382

6. Sofer M, Barghouthy Y, Bar-Yosef Y, Mintz I, Proietti S, Tsemah R, Horkin A Matzkin H, Giusti G (2017) Upper calyx accessibility through a lower calyx access is not influenced by morphometric and clinical factors in supine percutaneous nephrolithotomy. J Endourol 31(5):452-456

7. Autorino R, Giannarini G (2008) Prone or supine: is this the question? Eur Urol 54:1216-1218

8. Kumar P, Bach C, Kachrilas S, Papatsoris AG, Buchholz N, Masood J (2012) Supine percutaneous nephrolithotomy ( $\mathrm{PCNL})$ : 'in vogue' but in which position? BJU Int 110:1018-1021

9. Aghamir SM, Modaresi SS, Aloosh M, Tajik A (2011) Totally tubeless percutaneous nephrolithotomy for upper pole renal stone using subcostal access. J Endourol 25(4):583-586
10. Gupta R, Kumar A, Kapoor R, Srivastava A, Mandhani A (2002) Prospective evaluation of safety and efficacy of the supracostal approach for percutaneous nephrolithotomy. BJU Int 90:809-813

11. Sampaio FJ, Zanier JF, Aragão AH, Favorito LA (1992) Intrarenal access: 3-dimensional anatomical study. J Urol 148(6):1769-1773

12. Mak DK, Smith Y, Buchholz N, El-Husseiny T (2016) What is better in percutaneous nephrolithotomy_-Prone or supine? A systematic review. Arab J Urol 14(2):101-107

13. Guglielmetti GB, Danilovic A, Torricelli FC, Coelho RF, Mazzucchi E, Srougi M (2013) Predicting calyceal access for percutaneous nephrolithotomy with computed tomography multiplanar reconstruction. Clinics (Sao Paulo) 68(6):892-895

14. Patel RM, Okhunov Z, Clayman RV, Landman J (2017) Prone versus supine percutaneous nephrolithotomy: what is your position? Curr Urol Rep 18(4):26

15. Yuan D, Liu Y, Rao H, Cheng T, Sun Z, Wang Y, Liu J, Chen W, Zhong W, Zhu $J$ (2016) Supine versus prone position in percutaneous nephrolithotomy for kidney calculi: a meta-analysis. J Endourol 30(7):754-763

16. Kyriazis I, Panagopoulos V, Kallidonis P, Özsoy M, Vasilas M, Liatsikos E (2015) Complications in percutaneous nephrolithotomy. World J Urol 33(8):1069-1077

17. Seitz C, Desai M, Häcker A, Hakenberg OW, Liatsikos E, Nagele U, Tolley D (2012) Incidence, prevention, and management of complications following percutaneous nephrolitholapaxy. Eur Urol 61(1):146-158

18. Wu P, Wang L, Wang K (2011) Supine versus prone position in percutaneous nephrolithotomy for kidney calculi: a meta-analysis. Int Urol Nephrol 43(1):67-77

19. Liu L, Zheng S, Xu Y, Wei Q (2010) Systematic review and meta-analysis of percutaneous nephrolithotomy for patients in the supine versus prone position. J Endourol 24(12):1941-1946

20. Zhang X, Xia L, Xu T, Wang X, Zhong S, Shen Z (2014) Is the supine position superior to the prone position for percutaneous nephrolithotomy (PCNL)? Urolithiasis 42(1):87-93

\section{Publisher's Note}

Springer Nature remains neutral with regard to jurisdictional claims in published maps and institutional affiliations.

\section{Submit your manuscript to a SpringerOpen ${ }^{\circ}$ journal and benefit from:}

- Convenient online submission

- Rigorous peer review

- Open access: articles freely available online

- High visibility within the field

- Retaining the copyright to your article

Submit your next manuscript at springeropen.com 